\title{
Effectiveness of a Peer-Led Web-Based Intervention to Improve General Self-Efficacy in Using Dating Apps Among Young Adults: Randomized Clustered Trial
}

William CW Wong ${ }^{1,2}$, MD, MB ChB; Wai Han Sun ${ }^{3}$, MPhil, MSSc, BSocSci; Shu Ming Cheryl Chia ${ }^{2}$, MSc; Joseph D Tucker ${ }^{4,5}$, MD, DPhil; William PH Mak ${ }^{6}$, MSc; Lin Song ${ }^{7}$, DPhil; Kitty Wai Ying Choi ${ }^{3}$, BSocSC; Stephanie Tsz Hei Lau ${ }^{2}$, MPH; Eric Yuk Fai Wan ${ }^{2,8}$, DPhil

\footnotetext{
${ }^{1}$ Department of General Practice, University of Hong Kong-Shenzhen Hospital, Shenzhen, China

${ }^{2}$ Department of Family Medicine and Primary Care, University of Hong Kong, Hong Kong, China

${ }^{3}$ Sticky Rice Love Ltd., Hong Kong, China

${ }^{4}$ University of North Carolina at Chapel Hill - Project China, Guangzhou, China

${ }^{5}$ London School of Hygiene and Tropical Medicine, London, United Kingdom

${ }^{6}$ Vocational Training Council, Hong Kong, China

${ }^{7}$ Department of Communication, Faculty of Social Sciences, University of Macau, Macau, Macao

${ }^{8}$ Department of Pharmacology and Pharmacy, University of Hong Kong, Hong Kong, China
}

\section{Corresponding Author:}

William CW Wong, MD, MB ChB

Department of Family Medicine and Primary Care

University of Hong Kong

3/F, Ap Lei Chau Clinic, 161 Main Street, Ap Lei Chau,

Hong Kong

China

Phone: 85264883866

Email: wongwcw@hku.hk

\section{Abstract}

Background: Online dating apps are popular platforms for seeking romance and sexual relationships among young adults. As mobile apps can easily gain access to a pool of strangers ("new friends") at any time and place, it leads to heightened sexual health risks and privacy concerns.

Objective: This study aimed to evaluate the effectiveness of a peer-led web-based intervention for online dating apps to prepare Chinese college students so that they have better self-efficacy when using dating apps.

Methods: An open clustered randomized controlled trial was conducted among students from three colleges (The University of Hong Kong, Hang Seng University of Hong Kong, and Yijin Programme of Vocational Training College) in Hong Kong. Students aged 17 to 27 years who attended common core curriculum or general education were randomized into intervention and control groups. The intervention material, developed with high peer engagement, included four short videos, an interactive scenario game, and a risk assessment tool. An existing website promoting physical activities and healthy living was used as a control. Using the information, motivation, and behavioral skills (IMB) approach to design the evaluation, questionnaires covering participants' sociodemographics and dating app characteristics, as well as the general self-efficacy scale (GSE) as the primary outcome and the risk propensity scale (RPS) as the secondary outcome were administered before, immediately after, and at 1 month after the intervention. Intention-to-treat analysis was adopted, and between-group differences were assessed using the Mann-Whitney $U$ test. A post-hoc multiple linear regression model was used to examine the correlates of the GSE and RPS.

Results: A total of 578 eligible participants (290 in the intervention group and 288 in the control group) participated in the study with 36 lost to follow-up. There were more female participants $(318 / 542,58.7 \%)$ than male participants in the sample, reflecting the distribution of college students. Over half of the participants $(286 / 542,52.8 \%)$ reported the following reasons for using dating apps: being curious $(170 / 498,34.1 \%)$, trying to make new friends $(158 / 498,31.7 \%)$, and finding friends with similar interests $(121 / 498,24.3 \%)$. Overall, the participants in the intervention group reported favorable experiences when compared with the finding in the control group. There was significant improvement in the GSE score and reduction in the RPS score $(P<.001)$ in 
the intervention group. University of Hong Kong students were more susceptible to risk reduction after the intervention when compared with students from the other two institutions.

Conclusions: The online intervention was effective in improving general self-efficacy and reducing risk tendency among young students. Future work is needed to determine if this approach is cost-effective and such behavioral change is sustainable.

Trial Registration: ClinicalTrials.gov NCT03685643; https://clinicaltrials.gov/ct2/show/NCT03685643.

International Registered Report Identifier (IRRID)： RR2-10.1186/s13063-018-3167-5

(J Med Internet Res 2020;22(10):e16378) doi: 10.2196/16378

\section{KEYWORDS}

internet; sexual health; self-efficacy; young adult; risk assessment

\section{Introduction}

\section{Background of Online Dating Apps}

The use of online dating apps has become popular for seeking friendship and romantic and sexual relationships owing to the advancement of mobile technology and increased internet accessibility through smartphones. Many dating apps are free to download and embed a geolocation function that allows users to find nearby like-minded individuals. Through virtual communication platforms, users can easily meet friends and gain access to a wide pool of potential sexual partners at any place and time.

In the United States, there was an increase in the use of online or mobile dating apps by $4 \%$ in only 2 years (from $11 \%$ in 2013 to $15 \%$ in 2015) [1]. Young adults (aged 18-24 years) and older adults (aged 50-60 years) contributed most to the increase in dating app usage [1]. A more recent survey conducted in 2017 showed that $30 \%$ of adults aged 18 to 29 years were using dating apps [2]. Sumter and Vandenbosch found that 17\% of young adults had been using popular mobile dating apps, such as Tinder, Grindr, and Coffee meets Bagel in the past 2 years [3]. Online dating apps are also gaining popularity among Chinese youth [4]. It was reported that as many as two-fifth of millennials used online dating apps in Hong Kong [5]. Young adults (including university students) have been identified as the largest population group engaged in online dating.

Prior research found an increased level of risky sexual behavior among individuals who sought multiple partners through online domains [6]. According to Sawyer et al, young adults accounted for an estimated $50 \%$ of the 20 million new sexually transmitted infection (STI) cases per year, and less than half of them used condoms [7]. A local study found that dating app users were more likely to have multiple sexual partners and unprotected sex, resulting in an increased risk of STI [6]. Impulsivity has been consistently associated with risky sexual behavior, which contributes to the increasing rates of STI among young adults [8]. The characteristics of impulsive individuals usually involve living in the moment and less likelihood of delaying gratification. Hence, they are more likely to engage in activities that are seen as "fun" and "exciting," which are the characteristics of meeting someone online. Dating apps with built-in geolocation and instant messaging functions facilitate inner impulsivity among young adults to have social and even sexual interactions. In the case of dating apps, the lack of prescreening and instilling essential knowledge, attitudes, and behaviors among users could cause emerging concerns beyond public health. In our previous study, we found that dating app users could experience other nonhealth-related concerns, such as financial scams and privacy intrusion [9]. As sex education is not compulsory in Hong Kong schools but is provided on an ad hoc basis or as an extracurricular activity [10], the lack of training and awareness regarding dating app use could further expose these young people to the aforementioned risks.

\section{Peer-Led Approach and Crowdsourcing in Intervention Development}

Nowadays, many young adults gain sexual knowledge from their peers or the internet. Therefore, peer-led education, which is defined as "teaching or sharing of health information, values, and behaviors between individuals with shared characteristics such as social status, experience, and cultural backgrounds" [11], could be an effective strategy for disseminating sex education. It is an integrative approach that involves delivery of an intervention by peers of similar age in settings, such as community centers and youth clubs, using pedagogical or "diffusional" methods. Our systematic review and meta-analysis on peer-led sex education in developed countries demonstrated that peer-led education could effectively change sexual health knowledge and attitudes among young people [12].

In this study, a crowdsourcing method was adopted to form the backbone of this peer-led approach. Crowdsourcing is defined as having a group to solve a problem [13]. It is a tool that uses a bottom-up approach to facilitate and engage the community. Crowdsourcing allows a diverse group of individuals, including laypeople and experts, to contribute to public health interventions [14]. In addition to innovation, crowdsourcing discourages cognitive fixation, a process where people become focused upon others' ideas in a group setting, but forms a basis to allow development of promotional videos and images in a cooperative manner.

In collaboration with the research team and a nongovernmental organization (NGO) that specializes in online sex education (StickyRiceLove), a crowdsourcing contest called " "Hi, Stranger!' Dating Apps Education Design Contest" was conducted from December 2017 to April 2018 among students from the University of Hong Kong (HKU) enrolled in a common core course (Sexuality and Culture), as well as the members of a local NGO network called Sexuality Education Alliance. They were first asked to generate and submit ideas in the form of texts, images, videos, and websites. They were later evaluated 
based on the content, interactivity, creativity, and credibility by a team of experts made up of public health physicians and sociologists using a peer-vetted creative production approach [15]. The following five key risk domains were identified: sexual harassment, privacy, monetary issues, legal issues, and mental well-being. The synthesized results were used to develop the content and modes of delivery of the intervention in a design workshop by the peer volunteers from StickyRiceLove. Full details of the intervention development are published elsewhere [9].

\section{Study Aim and Hypothesis}

The aim of this study was to assess the effectiveness of a peer-led web-based intervention among young adults enrolled in three tertiary educational institutions in Hong Kong. The specific objectives were to evaluate the effectiveness and the participants' acceptability of the peer-led online intervention based on the changes in participants' emotions, awareness, attitudes, and behavioral skills in using dating apps. In addition, this study explored participants' sociodemographic factors and dating app characteristics as moderators of the primary outcome of the intervention (ie, general self-efficacy scale [GSE] score) and the secondary outcome (risk propensity scale [RPS] score). It was hypothesized that there would be a statistical difference between the intervention and control groups, in which the participants in the intervention group would have higher self-efficacy and a lower tendency to take risks 1 month after the intervention. In addition, differences in the education environment and mode of study among the tertiary institutions would affect the GSE and RPS scores.

\section{Methods}

\section{Study Design}

An open, clustered, randomized controlled trial (RCT) involving a peer-led safer sex intervention and control (1:1 allocation) was conducted among college students between September 2018 and May 2019. Allocation concealment was achieved through the sealed envelope method [16], and class clusters were randomly assigned to the two groups by an independent researcher. The study protocol and its design were approved by the Institutional Review Board of Hong Kong West Cluster and HKU (UW 18-369).

\section{Sampling Methods}

The inclusion criteria were as follows: (1) age 17 to 27 years and (2) first- or second-year college students enrolled into different tutorial groups or classes in the common core curriculum or general education courses in the three main tertiary educational institutions based in Hong Kong, namely the HKU, Hang Seng University of Hong Kong (HSUHK), and
Yijin Programme of Vocational Training College. Participants were excluded if they were color blind, had no access to a computer/internet literacy, and could not read/write Chinese.

The HKU is the oldest tertiary educational institution in Hong Kong and is regarded as one of the most prestigious universities in Asia, with five out of six applicants admitted being in the top $10 \%$ achievement ranking in the Hong Kong Examinations and Assessment Authority public examination. HSUHK is a nonprofit self-financed private university that offers undergraduate and taught postgraduate degrees, with five schools in the areas of business, communication, decision sciences, humanities and social science, and translation. The Yijin Programme is an alternative pathway for college education of generic skills including language, interpersonal skills, and communication offered to individuals who have completed high school or adult learners aged 21 years or above. Its qualification is accepted by government agencies as meeting academic entry requirements for civil service posts.

Based on the primary outcome of self-efficacy, a previous cluster RCT on school-delivered rights-based sexuality education for adolescents revealed a standard deviation of 0.56 and effect size of 0.20 [17]. Considering a minimal cluster size of 10 students, level of significance of .05 , power of 0.8 , and intracluster correlation coefficient of 0.007 , at least 338 students were required for this study, with a $30 \%$ assumed attrition rate.

\section{Intervention}

The final intervention involved four (2-4 min) short videos, an interactive scenario game, and a risk assessment tool (Multimedia Appendix 1, Multimedia Appendix 2, Multimedia Appendix 3, and Multimedia Appendix 4). The videos aimed to address the risks and benefits of using dating apps and encouraged the viewers to reflect on their perception of dating apps [9]. The first video illustrated similarities between meeting people on dating apps and in real life, providing examples of being misled by profile characteristics and monetary scams. The second video mainly targeted privacy concerns. The third demonstrated risky sexual behaviors associated with dating apps, and the fourth explained the legal issues and risks of sexual assault, including precautionary steps and available resources.

The scenario game depicted in Figure 1 is a first-person simulation game where the participant is presented with multiple choices when faced with real-life scenarios [9]. The game has been designed with various algorithms that result in both positive and adverse outcomes. A brief rationale for how player choices resulted in the outcomes would be indicated. Lastly, a risk assessment evaluation consisting of 14 questions would appear, and it would give the participant a score to infer the risk level for adverse events when using dating apps. 
Figure 1. Screenshots of the online game.

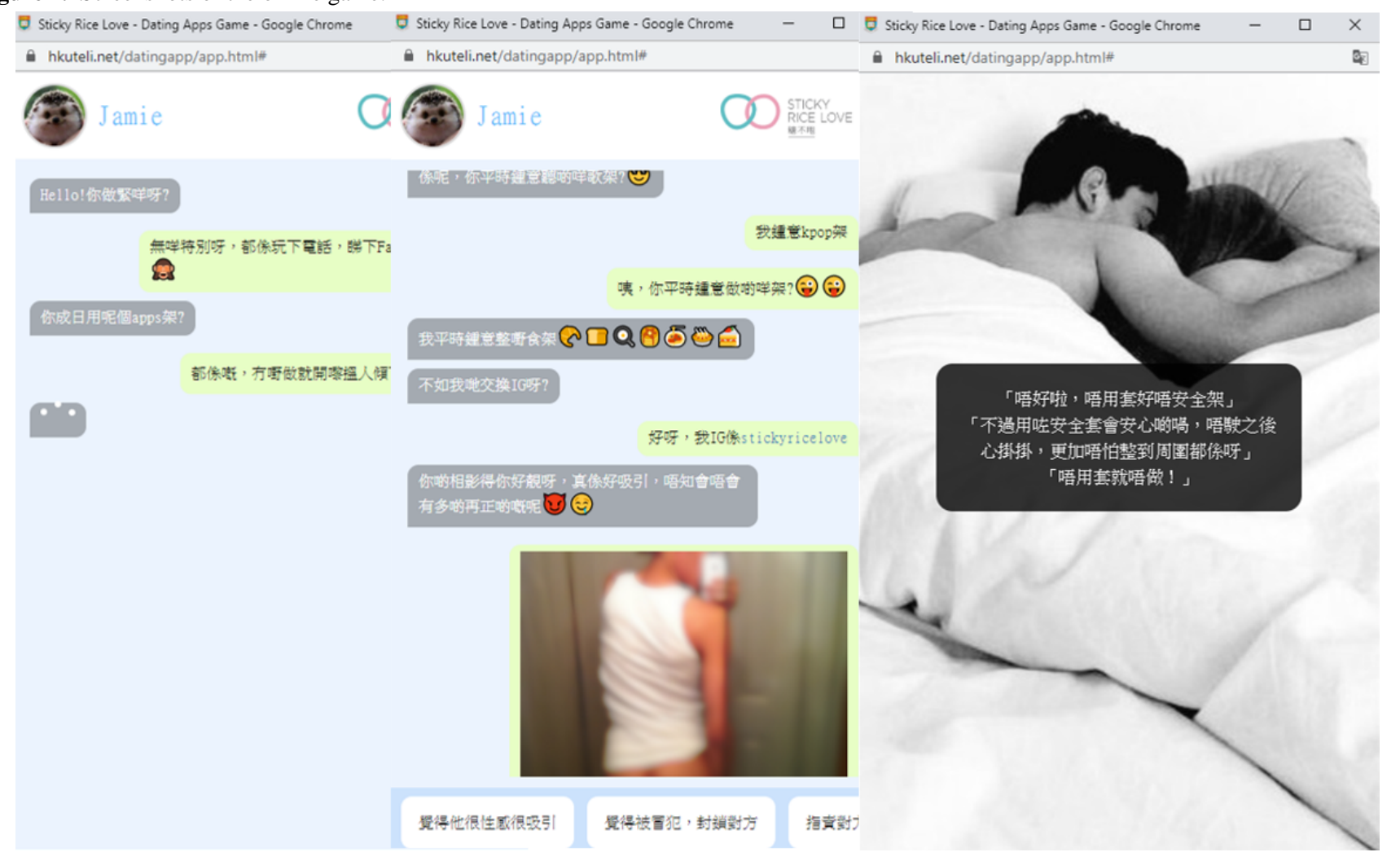

\section{Intervention Procedure}

According to the protocol, participants were informed about the voluntary nature of the assessment and that their refusal to participate would not affect their grades [18]. The participating students were asked not to share or discuss the interventions at the time of enrollment. A quasianonymous approach was used (ie, no login when accessing the intervention on the computer/mobile phone). Technical or logistical measures (eg, cookies, email confirmation, and phone calls) were not used to detect or prevent access.

After obtaining written consent, participants completed a preintervention online questionnaire, a postintervention questionnaire immediately after the intervention, and a follow-up questionnaire that encompassed questions relating to risk assessment 1 month later. The questionnaires were constructed and administered using a password-secured survey tool called SurveyGizmo to be accessed by a QR code using participants' mobile devices at their institutions. A reminder was sent to the students who did not complete the follow-up questionnaire after 1 week, and the questionnaire was closed 2 weeks after delivery. Upon completion, participants were given a HK $\$ 50$ (US $\$ 1=\mathrm{HK}$ $\$ 7.8$ ) coffee coupon as gratitude for participation.

In contrast, an existing Hong Kong government website promoting physical activity and healthy living was used in the control group. The "health exercise for all" campaign website has a similar modality as that in the intervention group (ie, videos and interactive games) to illustrate the different forms of exercise for different age groups and settings [19]. The game allows players to input personal information, including weight, gender, sports preference, and time spent on an individual sport with a personalized training diary and exercise tips.

\section{Evaluation}

The effectiveness of the intervention was guided by the information (facts, heuristics, and implicit theories), motivation (personal and social), and behavioral skills (self-efficacy and objective skills) (IMB) model [20]. The GSE includes 10 items for assessing one's ability to cope with a range of difficulties in daily life, correlated to one's self-belief, emotion, optimism, and work satisfaction [21]. The RPS rates general risk-taking tendencies with nine items on a 9-point Likert scale. A higher score indicates higher risk-taking tendencies [22]. Patient Health Questionnaire-2 (PHQ-2) is a two-item scale to assess the frequency of depressed mood and anhedonia over the previous 2 weeks, with preliminary screening for depressive symptoms [23]. In our study, the self-reported GSE was considered an appropriate primary outcome measure, as the GSE not only measures one's beliefs about their capabilities to control life events, such as finding a relationship or sexual partner online and achieving desirable outcomes, but is also related to social anxiety such that a negative GSE score indicates vulnerability to higher levels of stress when facing a difficult situation [24].

The preintervention questionnaire consisted of sociodemographic factors and dating app characteristics, such as age, gender, sexual orientation, relationship status, housing type, social media use, reasons to engage in dating apps, addiction risk, and unhappy encounters associated with dating apps (Multimedia Appendix 5). The postintervention questionnaire encompassed questions on acceptability of the intervention (ie, expressed interest, appropriateness of content, sufficient examples and explanation provided, cultivation of the participants' skills, continual use, and likelihood of recommendation to friends) (Multimedia Appendix 6). The follow-up questionnaire included questions matching those in 
the preintervention questionnaire, with additional questions regarding visitation frequency and actual recommendation to friends (Multimedia Appendix 7).

\section{Statistical Methods}

The demographics were described, and differences in baseline were assessed using chi-square tests for categorical variables (eg, age, gender, and sexual orientation) and $t$ tests for scaled outcomes. In order to conduct a chi-square test for the evaluation of the intervention's acceptability among the participants, five scaled options were categorized into two groups as follows: "strongly agree, agree, and neutral" and "strongly disagree and disagree." Students who did not complete the questionnaire were included for the analysis as per intention to treat (ITT), with "last observation carried forward" values adopted. Owing to the skewness distribution of the outcomes, the differences of intervention testing for mainly the GSE, RPS, and PHQ-2 at follow-up were assessed using the Mann-Whitney $U$ test. Univariate linear regression and multiple linear regression models were used to measure the association among the different confounding factors (eg, gender, relationship status, and reasons for using dating apps) against the primary and secondary outcomes. All data were entered, cleaned, and analyzed using SPSS (version 25; IBM Corp), and statistical significance was set at a $P$ value <.05.

\section{Results}

\section{Demographics and Dating App Statistics}

A total of 578 participants who completed the preintervention questionnaire were randomized into the intervention $(n=290)$ and control $(n=288)$ groups. Since common core curriculum and general education classes were compulsory courses, the response rate was generally very high $(215 / 240,89.5 \%$ for HKU; 183/200, 91.5\% for HSUHK; and 180/208 for Yijin Programme, $86.5 \%$ ). A total of 36 participants were lost to follow-up, giving rise to a dropout rate of $6.2 \%$ (Figure 2).

Figure 2. CONSORT flow diagram. HKU: University of Hong Kong; HSUHK: Hang Seng University of Hong Kong; VTC: Vocational Training College.

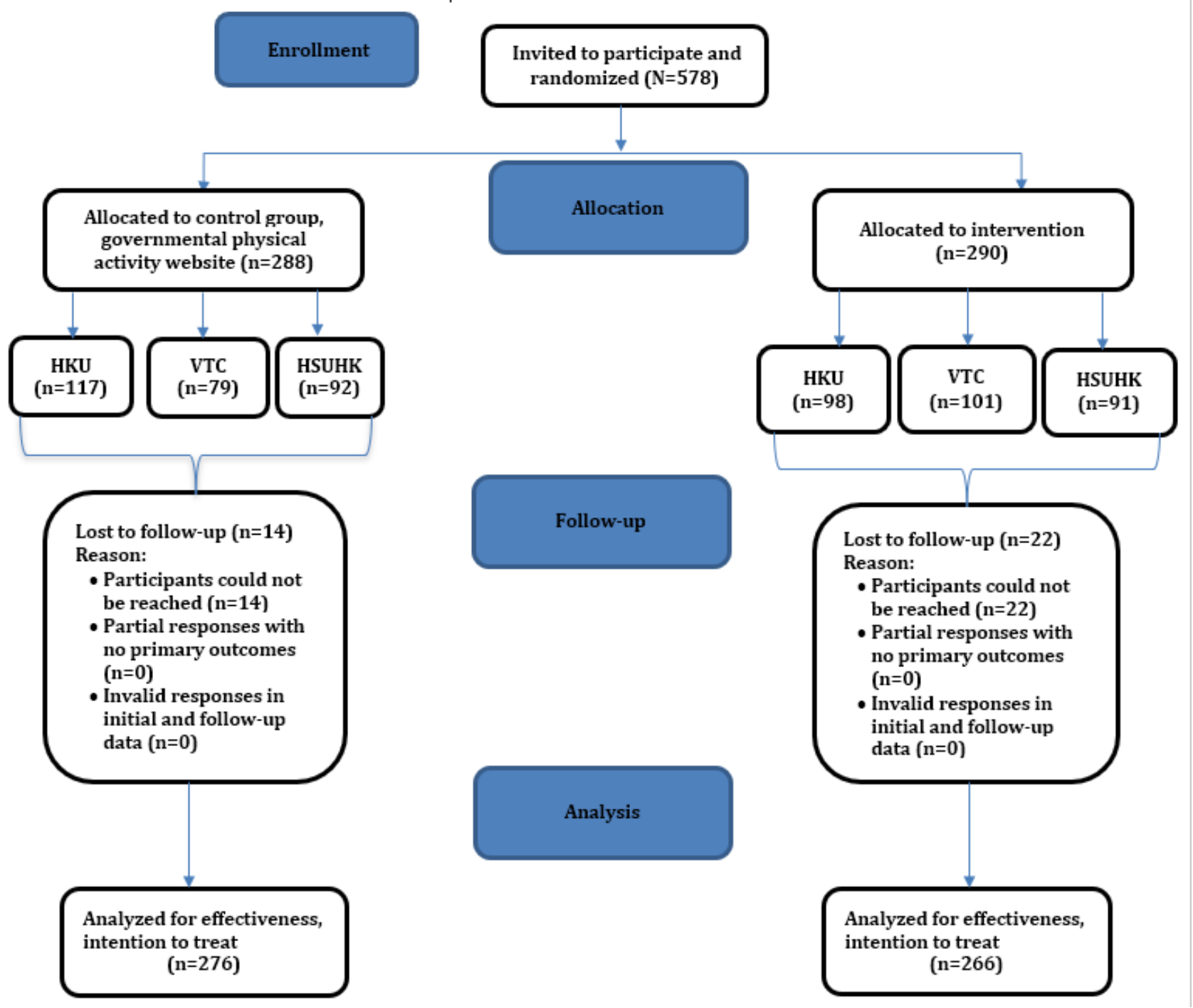

Participants in the intervention and control groups had a similar age profile (ie, mean 19.83 years, SD 1.9 years and mean 19.88 years, SD 1.8 years, respectively) (Table 1). There were more females $(318 / 542,58.7 \%)$ than males $(224 / 542,41.3 \%)$, reflecting the gender ratio in tertiary education $(53.3 \%$ females and $46.7 \%$ males pursuing undergraduate studies in 2017/2018, 
University Grants Committee). Most of the participants were heterosexual $(490 / 542,90.4 \%)$. Two-thirds of the recruited participants were single $(353 / 542,65.1 \%)$, and the remaining $(189 / 542,34.9 \%)$ were in some form of relationship. In addition, about one-third stayed at private accommodation (208/542, $38.4 \%)$ or public housing $(186 / 542,34.3 \%)$.

Table 2 presents the gathered responses pertaining to the participants' characteristics regarding dating apps. Nearly half of the recruited participants $(286 / 578,49.5 \%)$ were found to have visited dating websites. The participants suggested that internet $(258 / 606,42.6 \%)$ and friends $(266 / 606,43.9 \%)$ were the most popular means to gain information about dating apps according to a multiple response setting where the participants could select more than one choice per question. In addition, social media was highlighted by the responses as the most popular social networking platform across both the intervention and control groups (96/218, 44.0\% and 101/225, 44.9\%, respectively).
Being curious $(170 / 498,34.1 \%)$, trying to make new friends $(158 / 498,31.7 \%)$, and finding friends with similar interests $(121 / 498,24.3 \%)$ were popular selections made by the participants regarding what attracted them to engage in dating apps. Most of the dating app users responded that they did not face any discontent $(207 / 286,72.4 \%)$, except for a minority that faced privacy intrusion $(34 / 286,11.9 \%)$ and sexual assailment $(23 / 286,8.0 \%)$ before. More than half of the responses $(169 / 285,59.3 \%)$ highlighted that using dating apps to establish friendship required a longer time than anticipated. The participants perceived that dating apps had affected their work or school life $(106 / 285,37.2 \%)$, sleep $(125 / 285,43.9 \%)$, and relationship with their friends/family $(75 / 285,26.3 \%)$. At baseline, no relevant differences were found among the outcomes across the intervention and control groups $(P=.09$ to $P=.85)$.

Table 1. Baseline sociodemographic characteristics of the participating college students.

\begin{tabular}{|c|c|c|}
\hline Variable & Intervention group $(\mathrm{N}=290), \mathrm{n}(\%)$ or mean $(\mathrm{SD})$ & Control group $(\mathrm{N}=288), \mathrm{n}(\%)$ or mean $(\mathrm{SD})$ \\
\hline \multicolumn{3}{|l|}{ Gender } \\
\hline Female & $139(47.9 \%)$ & $179(62.2 \%)$ \\
\hline Male & $137(47.2 \%)$ & $87(30.2 \%)$ \\
\hline Not specified & $14(4.8 \%)$ & $22(7.6 \%)$ \\
\hline Age (years) & $19.83(1.9)$ & $19.88(1.8)$ \\
\hline \multicolumn{3}{|l|}{ Type of housing } \\
\hline Private apartment & $107(36.9 \%)$ & $101(35.1 \%)$ \\
\hline Public housing estates & $104(35.9 \%)$ & $82(28.5 \%)$ \\
\hline Subsided housing & $34(11.7 \%)$ & $39(13.5 \%)$ \\
\hline Student hostel & $19(6.6 \%)$ & $29(10.1 \%)$ \\
\hline Village & $7(2.4 \%)$ & $15(5.2 \%)$ \\
\hline Short interim & $5(1.7 \%)$ & $0(0 \%)$ \\
\hline Not specified & $14(4.8 \%)$ & $22(7.6 \%)$ \\
\hline \multicolumn{3}{|l|}{ Relationship status } \\
\hline Single & $183(63.1 \%)$ & $170(59.0 \%)$ \\
\hline Others (dating, married, or cohabitating) & $93(32.1 \%)$ & $96(33.3 \%)$ \\
\hline Not specified & $14(4.8 \%)$ & $22(7.6 \%)$ \\
\hline \multicolumn{3}{|l|}{ Sexual orientation } \\
\hline Heterosexual & $250(86.8 \%)$ & $240(83.3 \%)$ \\
\hline Others (gay, lesbian, or bisexual & $24(8.3 \%)$ & $26(9.0 \%)$ \\
\hline Not specified & $14(4.9 \%)$ & $22(7.6 \%)$ \\
\hline
\end{tabular}


Table 2. Characteristics of the responses from participants about their dating app use.

\begin{tabular}{|c|c|c|c|}
\hline Variable & $\begin{array}{l}\text { Intervention group }(\mathrm{N}=290), \mathrm{n} \\
(\%) \text { or mean }(\mathrm{SD})\end{array}$ & $\begin{array}{l}\text { Control group }(\mathrm{N}=288), \mathrm{n}(\%) \\
\text { or mean }(\mathrm{SD})\end{array}$ & $P$ value $^{\mathrm{a}}$ \\
\hline Ever used a dating website & & & .51 \\
\hline Yes & $139(47.9 \%)$ & $147(51.0 \%)$ & \\
\hline No & $151(52.1 \%)$ & $141(49.0 \%)$ & \\
\hline \multicolumn{4}{|l|}{ Source of information about dating apps } \\
\hline Internet & $118(34.8 \%)$ & $140(52.4 \%)$ & $<.001$ \\
\hline Friends & $147(43.3 \%)$ & $119(44.6 \%)$ & .82 \\
\hline Teachers or school staff & $52(15.3 \%)$ & $4(1.5 \%)$ & $<.001$ \\
\hline Magazine or fashion materials & $3(0.9 \%)$ & $2(0.7 \%)$ & .75 \\
\hline Family/parents & $19(5.6 \%)$ & $2(0.7 \%)$ & $<.001$ \\
\hline \multicolumn{4}{|l|}{ Social networking platforms } \\
\hline Social media platform (eg, Facebook and Instagram) & $96(44.0 \%)$ & $101(44.7 \%)$ & .49 \\
\hline Dating apps & $42(19.3 \%)$ & $77(62.1 \%)$ & $<.001$ \\
\hline Instant chatline (eg, WhatsApp and WeChat) & $78(35.8 \%)$ & $43(34.7 \%)$ & $<.001$ \\
\hline Others (eg, school and online game) & $2(0.9 \%)$ & $4(3.2 \%)$ & .03 \\
\hline \multicolumn{4}{|l|}{ Reasons for using dating apps } \\
\hline Making new friends & $73(29.9 \%)$ & $85(33.5 \%)$ & .38 \\
\hline Out of curiosity & $83(34.0 \%)$ & $87(35.6 \%)$ & .77 \\
\hline Finding friends with similar interest & $61(25.0 \%)$ & $60(24.5 \%)$ & .54 \\
\hline Sexual relationship & $11(4.5 \%)$ & $9(3.7 \%)$ & .59 \\
\hline Long-term relationship & $16(6.6 \%)$ & $13(5.3 \%)$ & .39 \\
\hline Encounter of unhappiness while using dating apps & & & .77 \\
\hline Yes & $38(27.3 \%)$ & $41(27.9 \%)$ & \\
\hline No & $101(72.6 \%)$ & $106(72.1 \%)$ & \\
\hline \multicolumn{4}{|l|}{ Types of problem encountered with dating apps } \\
\hline Financially scammed & $7(18.4 \%)$ & $5(12.5 \%)$ & .65 \\
\hline Cyberbully/blackmail & $5(12.3 \%)$ & $4(10.0 \%)$ & .74 \\
\hline Privacy issues & $15(39.5 \%)$ & $19(47.5 \%)$ & .86 \\
\hline Sexual assault & $11(28.9 \%)$ & $12(30.0 \%)$ & .73 \\
\hline \multicolumn{4}{|l|}{ Dating apps and their addiction implications } \\
\hline Time spent on dating app is longer than anticipated & & & .20 \\
\hline Disagree & $61(44.2 \%)$ & $55(37.4 \%)$ & \\
\hline Agree & $77(55.8 \%)$ & $92(62.6 \%)$ & \\
\hline Affect work or school life & & & .30 \\
\hline Disagree & $83(60.1 \%)$ & $96(65.3 \%)$ & \\
\hline Agree & $55(39.9 \%)$ & $51(34.7 \%)$ & \\
\hline Affect sleep & & & .83 \\
\hline Disagree & $77(55.8 \%)$ & $83(56.5 \%)$ & \\
\hline Agree & $61(44.2 \%)$ & $64(43.5 \%)$ & \\
\hline Affect relationship with friends/family & & & .67 \\
\hline Disagree & $104(25.2 \%)$ & $107(72.8 \%)$ & \\
\hline Agree & $35(74.8 \%)$ & $40(27.2 \%)$ & \\
\hline
\end{tabular}




\begin{tabular}{|c|c|c|c|}
\hline Variable & $\begin{array}{l}\text { Intervention group }(\mathrm{N}=290), \mathrm{n} \\
(\%) \text { or mean }(\mathrm{SD})\end{array}$ & $\begin{array}{l}\text { Control group }(\mathrm{N}=288), \mathrm{n}(\%) \\
\text { or mean (SD) }\end{array}$ & $P$ value $^{\mathrm{a}}$ \\
\hline \multicolumn{4}{|l|}{ Outcomes } \\
\hline $\mathrm{GSE}^{\mathrm{b}}$ & $23.95(5.25)$ & $22.65(4.85)$ & .27 \\
\hline $\mathrm{RPS}^{\mathrm{c}}$ & $5.96(0.95)$ & $5.97(0.90)$ & .85 \\
\hline PHQ-2 ${ }^{\mathrm{d}}$ & $3.86(1.33)$ & $4.10(1.38)$ & .09 \\
\hline
\end{tabular}

${ }^{\mathrm{a}} \mathrm{Chi}$-square test is used to compare the statistical difference in categorical variables between groups. Mann-Whitney $U$ test is also used.

${ }^{\mathrm{b}} \mathrm{GSE}$ : general self-efficacy scale.

${ }^{\mathrm{c}} \mathrm{RPS}$ : risk propensity scale.

${ }^{\mathrm{d}}$ PHQ-2: Patient Health Questionnaire.

\section{Intervention Evaluation Outcomes}

As presented in Table 3, the responses received indicated that the proportion of participants who became interested in the dating program was significantly higher in the intervention group $(162 / 410,39.5 \%)$ than in the control group $(88 / 410$, $21.5 \% ; P=.002)$. In addition, the proportion of participants who responded that the intervention provided sufficient explanations and examples was significantly higher in the intervention group (231/410, 56.3\%) than in the control group (129/410, 31.5\%; $P<.001)$. Moreover, the proportion of participants who responded that they would recommend the approach to their friends was significantly higher in the intervention group $(211 / 410,51.5 \%)$ than in the control group $(125 / 410,30.5 \%$; $P=.04)$. Furthermore, one-quarter of participants from the intervention group $(114 / 497,23.0 \%)$ and one-tenth of participants from the control group $(47 / 497,9.5 \%)$ had introduced the intervention to their friends $(P<.001)$.

After adjustment for the baseline GSE score, a significant difference was found between the intervention and control groups at the 1-month follow-up $(P<.001)$. A similar result trend is elicited especially in HSUHK, where a significant difference was observed $(P<.001)$. In addition, a small but significant $(P=.04)$ decrease in the GSE score by -0.03 for every 1 unit increase could be observed in the control group (Table 4).

Using the stepwise univariate regression analysis, dating apps and their addiction implications were found to have a positive association for affecting the RPS score $(P<.001)$ (Table 5). On the other hand, other factors having positive associations for affecting the GSE score were relationship status $(P=.02)$, reasons to use dating apps, in particular, seeking sexual relationships $(P=.002)$ and long term relationships $(P=.014)$, information about dating apps disseminated by teachers/school staff $(P=.02)$, and differences in gender $(P=.04)$. These significant factors were further analyzed using a backward multiple regression analysis, and it was found that there was a significant difference in the treatment group for the GSE score $(P<.001)$ and RPS score $(P<.001)$ (Table 6). In addition, HKU was found to be a significant confounding factor $(P=.006)$ negatively associated with the RPS score. 
Table 3. Feedback responses at postintervention.

\begin{tabular}{|c|c|c|c|}
\hline Variable & $\begin{array}{l}\text { Intervention group }(\mathrm{N}=276) \text {, } \\
\mathrm{n}(\%)\end{array}$ & $\begin{array}{l}\text { Control group }(\mathrm{N}=266), \mathrm{n} \\
(\%)\end{array}$ & $P$ value $^{\mathrm{a}}$ \\
\hline \multicolumn{4}{|c|}{ This intervention caused me to be interested in the dating program. } \\
\hline Disagree & $86(34.6 \%)$ & $74(45.7 \%)$ & .002 \\
\hline Agree & $162(65.3 \%)$ & $88(54.3 \%)$ & \\
\hline \multicolumn{4}{|c|}{ The content of the intervention is appropriate. } \\
\hline Disagree & $17(6.9 \%)$ & $18(11.1 \%)$ & .14 \\
\hline Agree & $231(93.1 \%)$ & $144(88.9 \%)$ & \\
\hline \multicolumn{4}{|c|}{ This intervention provided sufficient explanations and examples. } \\
\hline Disagree & $17(6.9 \%)$ & $33(20.4 \%)$ & $<.001$ \\
\hline Agree & $231(93.1 \%)$ & $129(79.6 \%)$ & \\
\hline \multicolumn{4}{|c|}{ This intervention has cultivated my ability and skills. } \\
\hline Disagree & $44(17.7 \%)$ & $33(20.4 \%)$ & .52 \\
\hline Agree & $204(82.3 \%)$ & $129(79.6 \%)$ & \\
\hline \multicolumn{4}{|c|}{ I will continue to use the intervention. } \\
\hline Disagree & $39(9.5 \%)$ & $37(9.0 \%)$ & .07 \\
\hline Agree & $209(50.1 \%)$ & $125(30.5 \%)$ & \\
\hline \multicolumn{4}{|c|}{ I will recommend this intervention to my friends. } \\
\hline Disagree & $37(15.7 \%)$ & $37(22.8 \%)$ & .04 \\
\hline Agree & $211(84.3 \%)$ & $125(77.2 \%)$ & \\
\hline \multicolumn{4}{|c|}{ Are there any beneficial effects with respect to the program? } \\
\hline Yes & $209(90.1 \%)$ & $188(81.7 \%)$ & .16 \\
\hline No & $23(9.9 \%)$ & $42(18.3 \%)$ & \\
\hline \multicolumn{4}{|c|}{ Are there any improvements to be made to the program? } \\
\hline Yes & $123(60.6 \%)$ & $141(61.5 \%)$ & .72 \\
\hline No & $80(39.4 \%)$ & $88(38.4 \%)$ & \\
\hline \multicolumn{4}{|c|}{ Have you visited the $\mathrm{HKU}^{\mathrm{b}}$ intervention website after the study? } \\
\hline Yes & $153(56.0 \%)$ & $130(57.0 \%)$ & .09 \\
\hline No & $120(43.9 \%)$ & $98(43.0 \%)$ & \\
\hline \multicolumn{4}{|c|}{ Have you recommended any friends after the intervention? } \\
\hline Yes & $114(42.7 \%)$ & $47(20.4 \%)$ & $<.001$ \\
\hline No & $153(57.3 \%)$ & $183(79.6 \%)$ & \\
\hline
\end{tabular}

${ }^{\mathrm{a}} \mathrm{Chi}$-square test is used to compare the statistical difference between groups.

${ }^{\mathrm{b}} \mathrm{HKU}$ : University of Hong Kong. 
Table 4. Effectiveness of the intervention in participating college students at the 1-month follow-up.

\begin{tabular}{|c|c|c|c|c|c|c|c|c|c|c|c|}
\hline \multirow[t]{2}{*}{ Scale } & \multicolumn{3}{|c|}{ Intervention $(\mathrm{N}=290)$, mean $(\mathrm{SD})$} & \multicolumn{3}{|c|}{ Control $(\mathrm{N}=288)$, mean $(\mathrm{SD})$} & \multicolumn{4}{|c|}{$\begin{array}{l}\text { Control vs intervention } \\
P \text { value }\end{array}$} & \multirow{2}{*}{$\begin{array}{l}\text { Univariate regres- } \\
\text { sion analysis } \\
P \text { value } \\
(95 \% \mathrm{CI})\end{array}$} \\
\hline & $\begin{array}{l}\mathrm{HKU}^{\mathrm{a}} \\
(\mathrm{n}=98)\end{array}$ & $\begin{array}{l}\mathrm{HSUHK}^{\mathrm{b}} \\
(\mathrm{n}=91)\end{array}$ & $\begin{array}{l}\text { VTC }^{c} \\
(n=101)\end{array}$ & $\begin{array}{l}\text { HKU } \\
(n=117)\end{array}$ & $\begin{array}{l}\text { HSUHK } \\
(n=92)\end{array}$ & $\begin{array}{l}\text { VTC } \\
(n=79)\end{array}$ & $\mathrm{HKU}$ & HSUHK & VTC & Total & \\
\hline $\mathrm{GSE}^{\mathrm{d}}$ & $\begin{array}{l}24.55 \\
(5.57)\end{array}$ & $\begin{array}{l}24.68 \\
(4.85)\end{array}$ & $\begin{array}{l}23.59 \\
(5.88)\end{array}$ & $\begin{array}{l}23.01 \\
(4.71)\end{array}$ & $\begin{array}{l}22.32 \\
(5.14)\end{array}$ & $\begin{array}{l}23.37 \\
(5.87)\end{array}$ & $.12^{\mathrm{e}}$ & $<.001^{\mathrm{e}}$ & $.53^{\mathrm{e}}$ & $<.001^{\mathrm{f}}$ & $\begin{array}{l}.04 \\
(-0.03 \text { to }-0.01)\end{array}$ \\
\hline $\mathrm{RPS}^{\mathrm{g}}$ & $\begin{array}{l}5.57 \\
(0.99)\end{array}$ & $\begin{array}{l}5.67 \\
(1.01)\end{array}$ & $\begin{array}{l}4.72 \\
(1.55)\end{array}$ & $\begin{array}{l}5.73 \\
(1.09)\end{array}$ & $\begin{array}{l}5.65 \\
(1.13)\end{array}$ & $\begin{array}{l}5.31 \\
(1.23)\end{array}$ & $.10^{\mathrm{e}}$ & $.97^{\mathrm{e}}$ & $.32^{\mathrm{e}}$ & $.12^{\mathrm{f}}$ & $\begin{array}{l}.06 \\
(0.02 \text { to } 0.09)\end{array}$ \\
\hline PHQ-2 ${ }^{\mathrm{h}}$ & $\begin{array}{l}4.24 \\
(1.41)\end{array}$ & $\begin{array}{l}3.78 \\
(1.34)\end{array}$ & $\begin{array}{l}4.55 \\
(1.52)\end{array}$ & $\begin{array}{l}4.09 \\
(1.31)\end{array}$ & $\begin{array}{l}3.77 \\
(1.15)\end{array}$ & $\begin{array}{l}4.30 \\
(1.51)\end{array}$ & $.47^{\mathrm{e}}$ & $.80^{\mathrm{e}}$ & $.26^{\mathrm{e}}$ & $.19^{\mathrm{f}}$ & $\begin{array}{l}.23 \\
(-0.05 \text { to } 0.01)\end{array}$ \\
\hline
\end{tabular}

${ }^{\mathrm{a}} \mathrm{HKU}$ : University of Hong Kong.

${ }^{\mathrm{b}}$ HSUHK: Hang Seng University of Hong Kong.

${ }^{\mathrm{c}}$ VTC: Vocational Training College.

${ }^{\mathrm{d}} \mathrm{GSE}$ : general self-efficacy scale.

e Mann-Whitney $U$ test is used to compare the statistical difference between groups within institutions.

${ }^{\mathrm{f}}$ Mann-Whitney $U$ test is used to compare the statistical difference between groups overall.

${ }^{\mathrm{g}} \mathrm{RPS}$ : risk propensity scale.

${ }^{\mathrm{h}} \mathrm{PHQ}-2$ : Patient Health Questionnaire-2. 
Table 5. Factors affecting the general self-efficacy scale and risk propensity scale scores using a univariate regression model.

\begin{tabular}{|c|c|c|c|c|}
\hline \multirow[t]{2}{*}{ Factor } & \multicolumn{2}{|c|}{ General self-efficacy scale score } & \multicolumn{2}{|c|}{ Risk propensity scale score } \\
\hline & Coefficient $\beta$ (95\% CI) & $P$ value $^{\mathrm{a}}$ & Coefficient $\beta$ (95\% CI) & $P$ value $^{\mathrm{a}}$ \\
\hline \multicolumn{5}{|l|}{ Sociodemographic factors } \\
\hline Age & $0.00(-0.23$ to 0.23$)$ & .98 & $-0.02(-0.08$ to 0.03$)$ & .34 \\
\hline \multicolumn{5}{|l|}{ Gender (ref ${ }^{b}$ : male) } \\
\hline Female & $-0.93(-1.79$ to -0.06$)$ & .04 & $0.11(-0.09$ to 0.32$)$ & .28 \\
\hline \multicolumn{5}{|l|}{ Housing type (ref: public housing) } \\
\hline Subsidized housing & $0.13(-1.11$ to 1.36$)$ & .84 & $0.19(-0.11$ to 0.48$)$ & .22 \\
\hline Private housing & $-0.51(-1.38$ to 0.36$)$ & .25 & $-0.20(-0.41$ to 0.01$)$ & .06 \\
\hline Short interim & $1.40(-3.88$ to 6.66$)$ & .60 & $-0.10(-1.49$ to 1.29$)$ & .87 \\
\hline Village & $2.08(-0.06$ to 4.21$)$ & .06 & $-0.25(-0.75$ to 0.26$)$ & .34 \\
\hline \multicolumn{5}{|l|}{ Sexual orientation (ref: heterosexual) } \\
\hline Gay/lesbian/bisexual & $-0.09(-1.56$ to 1.38$)$ & .90 & $0.02(-0.33$ to 0.37$)$ & .15 \\
\hline \multicolumn{5}{|l|}{ Relationship status (ref: single) } \\
\hline Dating/marriage/cohabitating & $0.10(0.12$ to 1.88$)$ & .03 & $-0.15(-0.36$ to 0.06$)$ & .37 \\
\hline \multicolumn{5}{|l|}{ Dating characteristics } \\
\hline \multicolumn{5}{|l|}{ Ever used dating apps (ref: yes) } \\
\hline No & $-0.69(-1.53$ to 0.14$)$ & .10 & $0.13(-0.06$ to 0.33$)$ & .18 \\
\hline \multicolumn{5}{|l|}{ Types of platforms to know friends (ref: dating apps) } \\
\hline \multicolumn{5}{|l|}{ Reasons for using dating apps (ref: curiosity) } \\
\hline New friends & $-0.62(-1.87$ to 0.63$)$ & .33 & $-0.11(-0.41$ to 0.19$)$ & .47 \\
\hline Similar interest & $-0.32(-1.53$ to 0.89$)$ & .60 & $-0.23(-0.07$ to 0.53$)$ & .14 \\
\hline Sexual relationship & $3.58(1.36$ to 5.80$)$ & .002 & $0.23(-0.36$ to 0.81$)$ & .45 \\
\hline Long-term relationship & $2.38(0.46$ to 4.27$)$ & .01 & $-0.13(-0.62$ to 0.37$)$ & .61 \\
\hline \multicolumn{5}{|l|}{ Types of media (ref: friends) } \\
\hline Internet & $-0.01(-0.90$ to 0.87$)$ & .98 & $0.05(-0.16$ to 0.26$)$ & .63 \\
\hline Teachers or school staff members & $-1.72(-3.17$ to -0.27$)$ & .02 & $-0.06(-0.41$ to 0.28$)$ & .72 \\
\hline Magazine or fashion materials & $0.11(-4.28$ to 4.50$)$ & .96 & $0.66(-0.48$ to 1.79$)$ & .26 \\
\hline Family/parents/government initiation & $0.18(-2.04$ to 2.39$)$ & .88 & $-0.01(-0.63$ to 0.43$)$ & .71 \\
\hline \multicolumn{5}{|l|}{ Dating apps and their online implications } \\
\hline Affect sleep & $-0.12(-0.62$ to 0.39$)$ & .65 & $0.26(0.12$ to 0.40$)$ & $<.001$ \\
\hline Spent a longer time than usual on a dating app & $-0.25(-0.76$ to 0.26$)$ & .84 & $0.35(0.16$ to 0.54$)$ & $<.001$ \\
\hline Affect work or school & $-0.31(-0.87$ to 0.25$)$ & .28 & $0.31(0.13$ to 0.49$)$ & $<.001$ \\
\hline Affect relationship with friends and family & $-0.61(-1.21$ to 0.00$)$ & .05 & $0.37(0.15$ to 0.56$)$ & $<.001$ \\
\hline
\end{tabular}

${ }^{\text {a }} P$ value is analyzed using univariate analysis.

ref: reference. 
Table 6. Factors affecting the general self-efficacy scale and risk propensity scale scores using a multiple linear regression model.

\begin{tabular}{|c|c|c|c|c|}
\hline & \multicolumn{2}{|c|}{ General self-efficacy scale score } & \multicolumn{2}{|c|}{ Risk propensity scale score } \\
\hline & Coefficient $\beta$ (95\% CI) & $P$ value $^{\mathrm{a}}$ & Coefficient $\beta$ (95\% CI) & $P$ value $^{\mathrm{a}}$ \\
\hline Intervention group & $-2.79(-4.65$ to -0.92$)$ & .004 & 0.453 (0.099 to 0.81$)$ & .01 \\
\hline \multicolumn{5}{|l|}{ Gender (ref ${ }^{b}:$ male $)$} \\
\hline Female & $-1.56(-3.42$ to 0.30$)$ & .98 & $\mathrm{~N} / \mathrm{A}^{\mathrm{c}}$ & $\mathrm{N} / \mathrm{A}$ \\
\hline \multicolumn{5}{|l|}{ School (ref: VTC ${ }^{\mathrm{d}}$ ) } \\
\hline HSUHK $^{\mathrm{e}}$ & $-0.03(-4.86$ to 4.81$)$ & .99 & $-0.37(-0.79$ to 0.06$)$ & .09 \\
\hline $\mathrm{HKU}^{\mathrm{f}}$ & 0.35 (-2.93 to 3.63$)$ & .83 & $-0.62(-1.06$ to -0.18$)$ & .006 \\
\hline \multicolumn{5}{|l|}{ Baseline outcomes } \\
\hline General self-efficacy scale & $-0.51(-0.68$ to -0.34$)$ & $<.001$ & N/A & N/A \\
\hline Risk propensity scale & N/A & N/A & $-0.39(-0.55$ to -0.22$)$ & $<.001$ \\
\hline
\end{tabular}

${ }^{\text {a }} P$ value is analyzed using multiple linear regression analysis.

${ }^{b}$ ref: reference.

${ }^{\mathrm{c}} \mathrm{N} / \mathrm{A}$ : not applicable.

${ }^{\mathrm{d}}$ VTC: Vocational Training College.

${ }^{\mathrm{e}} \mathrm{HSUHK}$ : Hang Seng University of Hong Kong.

${ }^{\mathrm{f}} \mathrm{HKU}$ : University of Hong Kong.

\section{Discussion}

\section{Principal Findings}

To the best of our knowledge, there has been limited research focusing on the awareness of online dating app risks among young adults. Most sex-related apps and dating apps contain no information about sexual health promotion [25]. This finding is consistent with the finding of another local study that the use of dating websites was common among Hong Kong college students, mostly for curiosity and seeking new friends [26]. The participants from the intervention group disclosed having a greater interest toward the peer-led intervention compared with participants from the control group. They felt that clear and sufficient examples were given as illustrations compared with participants from the control group. For outcome evaluation, the findings supported that the intervention could elicit significant changes in participants' GSE skills $(P=.04)$, as well as significant changes in risk-taking tendencies $(P=.06)$.

In our study, participants' GSE scores increased after the intervention, although the absolute difference was small. The small increase in the GSE score was important as an indication that the web-based intervention changed their understanding of perceived control over the usage of dating apps in a short duration of time. A positive GSE finding may also indicate that participants were less anxious about being "judged" by potential partners. They may feel less anxious owing to their ability to hold positive appraisals [24]. Young adults with higher GSE scores would feel more efficacious and less anxious when using dating apps. The promising result of our study regarding enhanced general self-efficacy toward online dating app use is consistent with the findings of a systematic review stipulating that high levels of peer participation in these types of interventions could greatly improve sex knowledge, attitude, general self-efficacy, and social norms [12]. The positive outcome exhibited could be related to the introduction of gamification in nongaming situations that made the intervention unique and appealing to the targeted youth. The use of real-life scenarios and humor in games and videos may have attracted and retained the participants' attention [27]. As a result, this motivated and improved users' experience and engagement [28]. This was in contrast to a slight deterioration in the GSE score by -0.02 for every 1 unit increase in the control group, suggesting that the impertinent content relating to physical activity was unable to provide knowledge and skills in relation to safer dating app use.

A significant negative change was found in the risk propensity tendency among the participants overall, especially among HKU participants $(P=.006)$ (Table 6), suggesting that the web-based intervention may influence young adults who already have strong interest in sexuality and sexual health or that more academically capable students may be more amicable to the intervention. Coupled with the strong emphasis of the potential adverse sexual health outcomes and the precautionary steps from the web-based intervention [25], the intervention may help students to be more cautious toward online dating apps. Such results were not observed among students from other colleges for whom the motivation for unsafe behavior could be attributed more strongly to benefits than to risk perception. On the other hand, it is well known that risk perception itself is insufficient to explain the risky behavior [29].

According to analysis of the online search threads, it was found that young adults may have a higher tendency to engage with the digital world to search for sexual health concerns; topics including sexual pleasure, puberty, menstruation, and transmission; and mechanisms of infection [27]. Therefore, with the successful implementation of our intervention, we hope that 
people of all ages, not just young adults, could benefit from this new innovative way of training on how to use dating apps safely.

\section{Strengths and Limitations}

The major strengths of the study include its randomized design, low attrition rate, and implementation of validated outcome measures to assess the effectiveness of our peer-led web-based intervention. The game stimulation allows participants to create a personal profile that can drive tailoring functions and personalized messages. With the incorporation of risks and benefits in this peer-led web-based intervention, it could serve as a practical approach to shape and instill online dating app users with right values.

In contrast, the participants recruited in the selected universities may not be representative of the whole youth population. Further, peer-led education is effective in establishing safer sex norms and attitudes than adult-led interventions, but less so in imparting factual knowledge [30]. Although self-reported measures are common and practical methods to obtain information in behavioral health studies, self-reporting bias may be introduced, especially under-reporting the sensitive nature of sexual behavior [31]. Multiple entries were still possible despite the prohibition of duplicate responses from identical IP addresses. Lastly, the limited timeframe and exposure of the intervention may make it unable to capture any long-term changes in the intensity, frequency, or context of participants' emotions. Therefore, a longer intervention period is required for significant and sustainable changes in outcomes at the risk of high attrition rates. In theory, contamination could occur as participants from the control and intervention groups attended the same class, which could result in undermining of the effect magnitude of the intervention.

\section{Implications and Recommendations}

With the increasing popularity of mobile technology and the internet, this multifaceted intervention could serve as a starting point for novel interventions to increase safety awareness when seeking sexual partners online. Continuing to document dating app users' experiences through testimonials or videos demonstrated on the intervention website may increase general self-efficacy and reduce the risk tendency toward dating app use. The results obtained from the study could be insightful for public health practitioners and app companies to improve the safety profile of dating apps. Furthermore, novel delivery methods, such as social media and community-based centers, could be considered to reach out to an extensive youth population beyond the college setting. Health professionals could also share and update any new research findings pertaining to the detrimental health impacts associated with casual sex to deter users from risky sexual behavior through dating apps and to create a long-lasting unfavorable outlook about it. Lastly, trial-based health economic evaluation was not conducted in this study, and a previous study showed that a peer-led approach could be potentially more expensive than an adult-led initiative (i.e. $€ 28.2$ [US \$33.8] per target student in the peer-led group vs $€ 11.6$ [US \$13.9] in the teacher-led arm) [32]. Therefore, it is important to further investigate the cost-effectiveness, barriers, opportunities, and supporting measures to sustain the intervention in the long term by placing more emphasis on feedback from all stakeholders (eg, students, teachers, and members of the school) to allow the development of programs that are culturally and socially appropriate.

\section{Conclusion}

This study demonstrated that a peer-led intervention could improve short-term self-efficacy and reduce risk propensity in using dating apps among young Chinese adults. It is important to evaluate the motivations for using dating apps and attempt to understand the underlying mechanism between using dating apps and associated risks. Future work is needed to determine how to maintain behavioral change over a longer duration, how to reach underserved populations using different means, and how to disseminate such an intervention on a large scale.

\section{Acknowledgments}

The authors wish to thank the study participants and staff from The University of Hong Kong and StickyRiceLove organization, who made this work possible. We are thankful to the students of Hang Seng University of Hong Kong and Yijin Programme of Vocational Training College who participated in this study. We also want to thank Miss Chow Long Ching Bellavista for being part of the team that assisted in the delivery of the intervention. This study was funded by The Healthcare and Promotion Fund Scheme of the Government of Hong Kong (grant number: 09160275). The funding body was not involved in the design of the study or data collection. It was also not involved in the analysis, interpretation of data, or writing of the manuscript.

\section{Authors' Contributions}

WW designed the study, applied for funding, oversaw the whole implementation, supervised the data analysis, edited the manuscript, and provided feedback on the manuscript. LS, CKWY, and LSTH developed and carried out the intervention and evaluation of the tools. SWH and MWP recruited the participants and followed up with them. SWH applied for funding. CSMC conducted the statistical analysis under WYF's guidance. CSMC drafted and edited the manuscript. TJD provided advice on the crowdsourcing materials. All authors read and approved the manuscript.

\section{Conflicts of Interest}

None declared. 


\section{Multimedia Appendix 1}

Video illustrating similarities between meeting people on dating apps and in real life. Examples of being misled by profile characteristics and monetary scams.

[MOV File , 49616 KB-Multimedia Appendix 1]

\section{Multimedia Appendix 2}

Video depicting privacy concerns related to dating apps.

[MOV File, 37196 KB-Multimedia Appendix 2]

\section{Multimedia Appendix 3}

Video depicting risky sexual behavior.

[MOV File , 45974 KB-Multimedia Appendix 3]

\section{Multimedia Appendix 4}

Video depicting legal issues and risks of sexual assault, including precautionary steps and available resources.

[MOV File, 42172 KB-Multimedia Appendix 4]

\section{Multimedia Appendix 5}

Preintervention questionnaire.

[DOCX File, 30 KB-Multimedia Appendix 5]

\section{Multimedia Appendix 6}

Postintervention questionnaire.

[DOCX File, 19 KB-Multimedia Appendix 6]

\section{Multimedia Appendix 7}

Follow-up intervention questionnaire.

[DOCX File , 27 KB-Multimedia Appendix 7]

\section{References}

1. Tran A, Suharlim C, Mattie H, Davison K, Agénor M, Austin SB. Dating app use and unhealthy weight control behaviors among a sample of U.S. adults: a cross-sectional study. J Eat Disord 2019 May 31;7(1):16 [FREE Full text] [doi: 10.1186/s40337-019-0244-4] [Medline: 31164984]

2. Yi S, Te V, Pengpid S, Peltzer K. Social and behavioural factors associated with risky sexual behaviours among university students in nine ASEAN countries: a multi-country cross-sectional study. SAHARA J 2018 Dec;15(1):71-79 [FREE Full text] [doi: 10.1080/17290376.2018.1503967] [Medline: 30058474]

3. Sumter S, Vandenbosch L. Dating gone mobile: Demographic and personality-based correlates of using smartphone-based dating applications among emerging adults. 2018 Oct 20;21(3):655-673 [FREE Full text] [doi: 10.1177/1461444818804773]

4. Four in ten Hong Kongers have used internet dating Internet. YouGov. 2017. URL: https://hk.yougov.com/en-hk/news/ 2017/11/23/internet-dating/ [accessed 2019-06-10]

5. Sexual Behaviour. The Government of the Hong Kong Special Administrative Region (Centre for Health Protection). 2017. URL: https://www.chp.gov.hk/en/statistics/data/10/757/5520.html [accessed 2019-06-01]

6. Choi EP, Wong JY, Lo HH, Wong W, Chio JH, Fong DY. The Impacts of Using Smartphone Dating Applications on Sexual Risk Behaviours in College Students in Hong Kong. PLoS One 2016 Nov 9;11(11):e0165394 [FREE Full text] [doi: 10.1371/journal.pone.0165394] [Medline: 27828997]

7. Sawyer A, Smith E, Benotsch E. Dating Application Use and Sexual Risk Behavior Among Young Adults. Sex Res Soc Policy 2017 Sep 6;15(2):183-191 [FREE Full text] [doi: 10.1007/s13178-017-0297-6]

8. Hayaki J, Anderson B, Stein M. Sexual risk-taking mediates the association between impulsivity and acquisition of sexually transmitted infections among hazardously drinking incarcerated women. Am J Addict 2012 Nov;21 Suppl 1(1):S63-S71 [FREE Full text] [doi: 10.1111/j.1521-0391.2012.00296.x] [Medline: 23786513]

9. Wong W, Song L, See C, Lau S, Sun W, Choi W, et al. Using Crowdsourcing to Develop a Peer-Led Intervention for Safer Dating App Use: Pilot Study. JMIR Form Res 2020 Apr 21;4(4):e12098 [FREE Full text] [doi: 10.2196/12098] [Medline: 32314975]

10. Che FS. A study of the implementation of sex education in Hong Kong secondary schools. Sex Education 2005 Aug;5(3):281-294 [FREE Full text] [doi: 10.1080/14681810500171458] 
11. MacDowall W, Bonnell C, Davies M. Health Promotion Practice. London, UK: Open University Press; 2006.

12. Sun WH, Miu HY, Wong CK, Tucker JD, Wong WC. Assessing Participation and Effectiveness of the Peer-Led Approach in Youth Sexual Health Education: Systematic Review and Meta-Analysis in More Developed Countries. J Sex Res 2018 Jan 29;55(1):31-44. [doi: 10.1080/00224499.2016.1247779] [Medline: 27898248]

13. Tucker J, Day S, Tang W, Bayus B. Crowdsourcing in medical research: concepts and applications. PeerJ 2019;7:e6762 [FREE Full text] [doi: 10.7717/peerj.6762] [Medline: $\underline{\text { 30997295] }}$

14. Tang W, Wei C, Cao B, Wu D, Li KT, Lu H, et al. Crowdsourcing to expand HIV testing among men who have sex with men in China: A closed cohort stepped wedge cluster randomized controlled trial. PLoS Med 2018 Aug;15(8):e1002645 [FREE Full text] [doi: 10.1371/journal.pmed.1002645] [Medline: $\underline{\text { 30153265] }}$

15. Brabham DC, Ribisl KM, Kirchner TR, Bernhardt JM. Crowdsourcing applications for public health. Am J Prev Med 2014 Feb;46(2):179-187. [doi: 10.1016/j.amepre.2013.10.016] [Medline: 24439353]

16. Rohrbach LA, Berglas NF, Jerman P, Angulo-Olaiz F, Chou C, Constantine NA. A Rights-Based Sexuality Education Curriculum for Adolescents: 1-Year Outcomes From a Cluster-Randomized Trial. J Adolesc Health 2015 Oct;57(4):399-406. [doi: 10.1016/j.jadohealth.2015.07.004] [Medline: 26403840]

17. Dettori J. The random allocation process: two things you need to know. Evid Based Spine Care J 2010 Dec;1(3):7-9 [FREE Full text] [doi: 10.1055/s-0030-1267062] [Medline: 22956922]

18. Lau ST, Choi KW, Chen J, Mak WP, Yeung HK, Tucker J, et al. Study protocol for a peer-led web-based intervention to promote safe usage of dating applications among young adults: a cluster randomized controlled trial. Trials 2019 Feb 06;20(1):102 [FREE Full text] [doi: 10.1186/s13063-018-3167-5] [Medline: 30728064]

19. Healthy exercise for all campaign. Leisure and Cultural Services Department. 2014. URL: https://www.lcsd.gov.hk/en/ healthy/ [accessed 2019-06-01]

20. Fisher WA, Fisher JD, Rye BJ. Understanding and promoting AIDS-preventive behavior: Insights from the theory of reasoned action. Health Psychology 1995;14(3):255-264. [doi: 10.1037/0278-6133.14.3.255]

21. Schwarzer R, Jerusalem M. Generalized self-efficacy scale. In: Weinman J, Wright S, Johnston M, editors. Measures in health psychology: A user's portfolio. Windsor, UK: NFER-Nelson; 1995:35-37.

22. Meertens R, Lion R. Measuring an Individual's Tendency to Take Risks: The Risk Propensity Scale. J Appl Social Pyschol 2008 Jun;38(6):1506-1520 [FREE Full text] [doi: 10.1111/j.1559-1816.2008.00357.x]

23. Kroenke K, Spitzer RL, Williams JB. The Patient Health Questionnaire-2: validity of a two-item depression screener. Med Care 2003 Nov;41(11):1284-1292. [doi: 10.1097/01.MLR.0000093487.78664.3C] [Medline: 14583691]

24. Pitcho-Prelorentzos S, Heckel C, Ring L. Predictors of social anxiety among online dating users. Computers in Human Behavior 2020 Sep;110:106381 [FREE Full text] [doi: 10.1016/j.chb.2020.106381]

25. Huang ET, Williams H, Hocking JS, Lim MS. Safe Sex Messages Within Dating and Entertainment Smartphone Apps: A Review. JMIR Mhealth Uhealth 2016 Nov 08;4(4):e124 [FREE Full text] [doi: 10.2196/mhealth.5760] [Medline: 27826133]

26. Chan LS. Who uses dating apps? Exploring the relationships among trust, sensation-seeking, smartphone use, and the intent to use dating apps based on the Integrative Model. Computers in Human Behavior 2017 Jul;72:246-258. [doi: 10.1016/j.chb.2017.02.053]

27. Bailey J, Mann S, Wayal S, Hunter R, Free C, Abraham C, et al. Sexual health promotion for young people delivered via digital media: a scoping review. Public Health Res 2015 Nov;3(13):1-120. [doi: 10.3310/phr03130] [Medline: 26583166]

28. Wakefield M, Loken B, Hornik R. Use of mass media campaigns to change health behaviour. The Lancet 2010 Oct;376(9748):1261-1271 [FREE Full text] [doi: 10.1016/s0140-6736(10)60809-4]

29. Hanoch Y, Johnson JG, Wilke A. Domain specificity in experimental measures and participant recruitment: an application to risk-taking behavior. Psychol Sci 2006 Apr 06;17(4):300-304. [doi: 10.1111/j.1467-9280.2006.01702.x] [Medline: 16623686]

30. Mellanby A, Newcombe R, Rees J, Tripp J. A comparative study of peer-led and adult-led school sex education. Health Educ Res 2001 Aug;16(4):481-492 [FREE Full text] [doi: 10.1093/her/16.4.481] [Medline: 11525394]

31. Schroder KE, Carey MP, Vanable PA. Methodological challenges in research on sexual risk behavior: II. Accuracy of self-reports. Ann Behav Med 2003 Oct;26(2):104-123 [FREE Full text] [doi: 10.1207/S15324796ABM2602 03] [Medline: 14534028]

32. Borgia P, Marinacci C, Schifano P, Perucci CA. Is peer education the best approach for HIV prevention in schools? Findings from a randomized controlled trial. J Adolesc Health 2005 Jun;36(6):508-516. [doi: 10.1016/j.jadohealth.2004.03.005] [Medline: $\underline{15901516}$ ]

\section{Abbreviations}

GSE: general self-efficacy scale

HKU: University of Hong Kong

HSUHK: Hang Seng University of Hong Kong

NGO: nongovernmental organization

PHQ-2: Patient Health Questionnaire-2 
RCT: randomized controlled trial

RPS: risk propensity score

STI: sexually transmitted infection

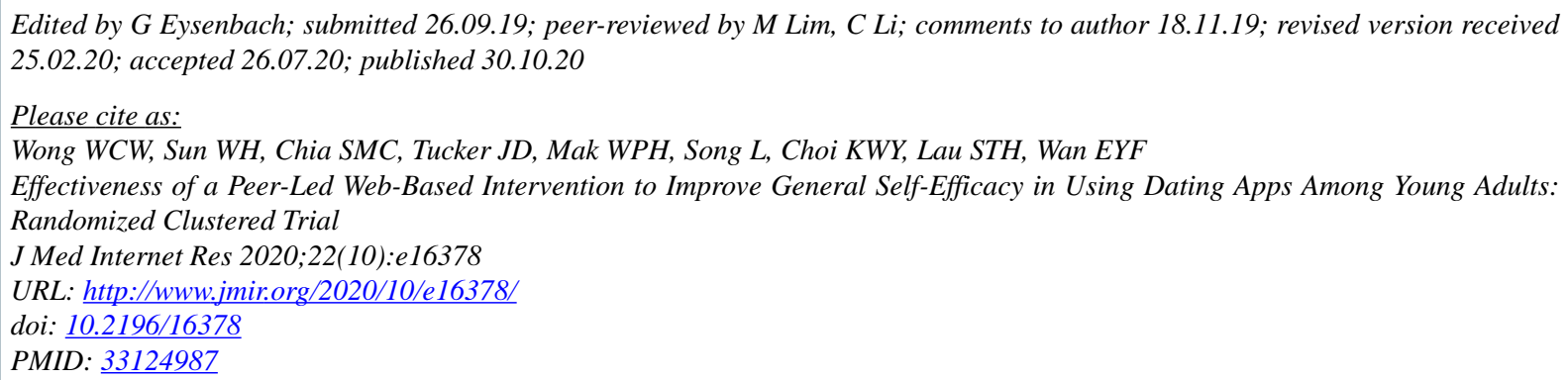

CWilliam CW Wong, Wai Han Sun, Shu Ming Cheryl Chia, Joseph D Tucker, William PH Mak, Lin Song, Kitty Wai Ying Choi, Stephanie Tsz Hei Lau, Eric Yuk Fai Wan. Originally published in the Journal of Medical Internet Research (http://www.jmir.org), 30.10.2020. This is an open-access article distributed under the terms of the Creative Commons Attribution License (https://creativecommons.org/licenses/by/4.0/), which permits unrestricted use, distribution, and reproduction in any medium, provided the original work, first published in the Journal of Medical Internet Research, is properly cited. The complete bibliographic information, a link to the original publication on http://www.jmir.org/, as well as this copyright and license information must be included. 